\title{
Geothermal heat use to eliminate hydrate formations in oil deposit injection wells
}

\author{
Mykhailo Fyk ${ }^{1}$, Volodymyr Biletskyi ${ }^{1 *}$, Madjid Abbood ${ }^{1}$, and Fabris Anzian ${ }^{2}$ \\ ${ }^{1}$ National Technical University "Kharkiv Polytechnic Institute", Department of Oil, Gas and Condensate \\ Extraction, 2 Kyrpychova St, 61002, Kharkiv, Ukraine \\ ${ }^{2}$ International University of Grand Bassam, School of Science, Technology, Engineering and \\ Mathematic (STEM), PoBox 564 Grand Bassam, Cote D'Ivoire
}

\begin{abstract}
The article is devoted to an actual issue: the development of internal downhole heat exchangers technology to combat hydration in injection wells. Purpose: development of conceptual solutions for the use of geothermal coolant in the internal well heat exchanger of the injection well. A scheme of an internal downhole heat exchanger with a geothermal heat carrier has been developed, and includes a supply line of a geothermal carrier through the heat exchange surface of the injection well into the productive reservoir of the oil field. The scheme provides targeted utilization of thermobaric energy of a geothermal source to combat hydration in the injection well. A mathematical apparatus for describing the process of heat utilization and heat exchange in injection well is proposed. It is established that the capacity of one geothermal well discovered at the oil depths in the Dnipro-Donetsk basin is sufficient to eliminate hydration in 1-3 injection wells, and determines the feasibility of their joint work.
\end{abstract}

\section{Introduction}

Hydrates of a mixture of hydrocarbons and water are formed in injection gas wells on oil fields under certain pressure and temperature conditions (PTC) and chemical composition [1-3]. If the hydrate formation clogs the injection column or bottomhole zone, it leads to economic losses.

The study of hydrate formation problem in the technological lines of downhole wells and bottomhole zone is of the highest relevance. The search for strategies and methods of eliminating excess hydrate formation, for different regime and technological conditions of oil field development, increases in depletion conditions of explored oil reserves in the world [4-20]. This is due, in particular, to the increasing need for flooding and injection of various gases compositions into depleted deposits to intensify oil production.

During the operation of an oil field with an anticlinal type deposit in the flooding regime, the bottom holes of injection and production wells are placed in accordance with Fig. 1. The reservoir area of the development object includes three main parts: gas-saturated, oilsaturated and water-saturated, the corresponding volumes of which $V_{\text {gas }}, V_{\text {oil }}, V_{\text {water }}$ change

*Corresponding author: biletsk@i.ua 


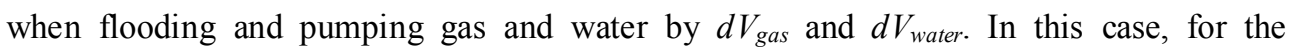
development object with a total volume of $V$,

$$
\begin{aligned}
& d V_{\text {oil }}=-\left(d V_{\text {gas }}+d V_{\text {water }}\right) ; \\
& V_{\text {gas }}+V_{\text {oil }}+V_{\text {water }}=V-\text { const } .
\end{aligned}
$$

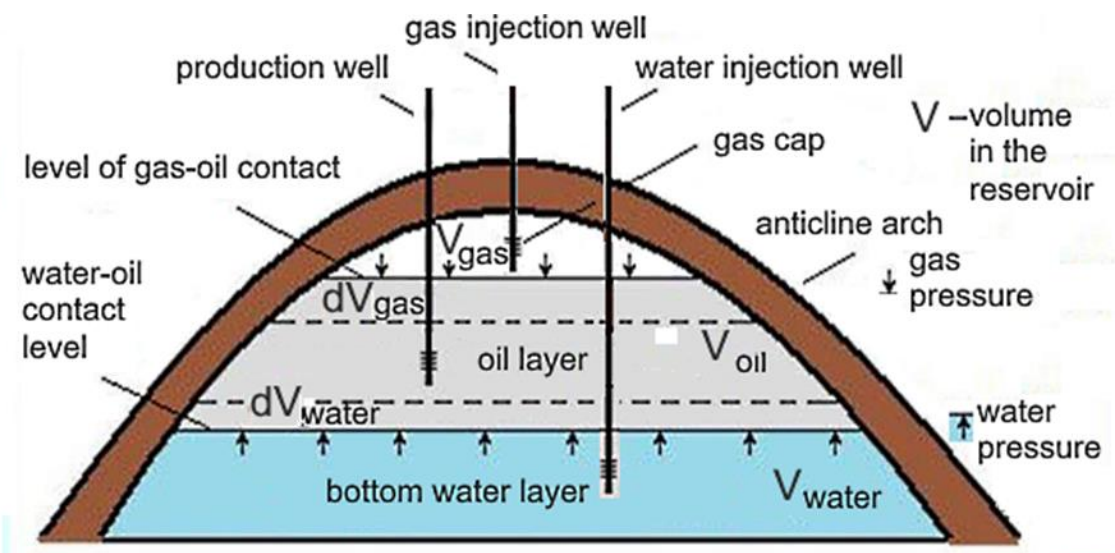

Fig. 1. Development scheme of an oil field with contour flooding and maintenance of pressure in a gas cap.

The diagram in Fig. 1 shows the water-oil and gas-oil contacts, which change according to (1) and (2). In injection wells, hydrates are formed in the column, at the bottom and in the bottomhole zone [4] (Fig. 2). The figure shows the crystalline structure of the gas hydrate and the numbered hydration zones No. 1-3 are highlighted in red.

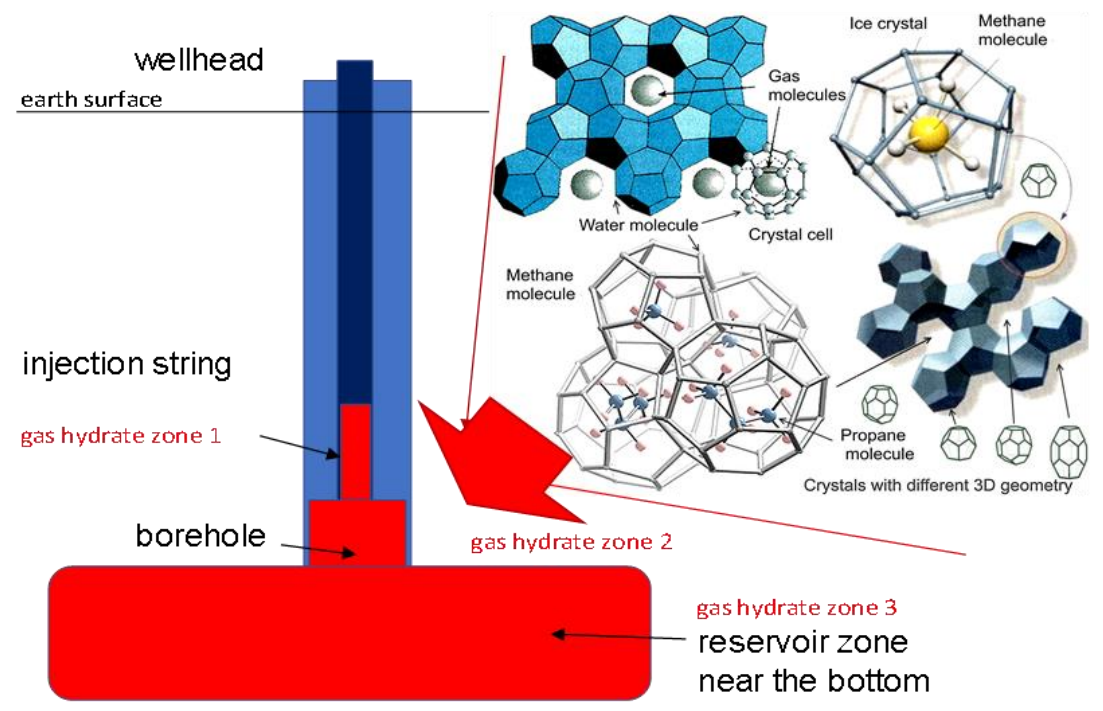

Fig. 2. Formation zone of gas hydrates in the injection gas well. 
When injecting gas, which is not sufficiently dried and heated, there is a process of throttling the gas in the column and in the formation medium, when reaching the point of hydration formation becomes a problem.

To avoid hydration and elimination of gas hydrates, shown in Fig. 2, dehumidification, increasing the temperature of the gas in the injection stream; reducing its pressure, the introduction of thermodynamic inhibitors of hydration (methanol, glycol, etc.), kinetic inhibitors and anti-agglomerates are used [5-8]. The operation of the injection well has a fixed plug of the pressure regime, that is, logically, to increase the gas temperature in the lower part of the column and in the bottomhole zone.

The problem of regulating the flow temperature in a porous hydrocarbon-saturated medium to reduce the growth of gas hydrate zone 3 (Fig. 2) on the one hand, and maximize the mass flow rate through the injection circuit on the other is known [9]. It is solved using heaters and heat exchangers. But the calculation of the amount of energy required for such heating is intensive and requires careful analysis of the main factors.

The study of the conditions for the hydrates formation of a natural gas mixture with water and some artificial impurities is given considerable attention due to its importance for oil and gas wells operation. In [10], it was shown that a small change in the percentage of impurities leads to a significant change in the temperature of hydration. In [9-11] it is emphasized that important factors of hydrate formation in addition to the composition of natural gas are under pressure and temperature conditions and capillary phenomena.

The dependence of hydrate formation on impurities composition [10] and different water saturation of reservoir rocks [11] complicates the accumulation forecast of hydrate formations in the porous medium.

When pumping cold gas into a porous medium, modeling the formation of hydrates is one of the most important industrial and scientific-applied tasks, which requires the involvement of tools for applied fluid mechanics and theoretical physics [12]. Basic and improved methods for predicting the formation of hydrates in pipeline injection lines, through which cold gas enters the porous medium, are covered in branch applied scientific journals of oil and gas profile [13].

Combined methods of combating hydration in injection wells on oil fields with hydration inhibitors and gas heating, using heat exchange systems, have become widespread [21]. But direct natural gas heating in the wells by electric heaters is not used by many oil companies due to distrust in the complete internal well electric heaters safety [22].

One of the promising areas of combating hydration in injection wells are internal downhole heat exchangers $[23,24]$. Heat exchangers, in contrast to electric heaters, allow separating the heat source from the explosive gas environment as safely as possible.

The increase of the heat exchange surface between the injection columns within the framework of the combined injection of thermal and pressure agents, as well as inhibitors of hydrate formation, the establishment of a rational balance of formation and destruction of gas hydrates are important applications in the development of oil deposits.

Thus, the review and analysis confirm the presence of an urgent problem: the development of technologies of internal well heat exchangers to eliminate hydration in injection wells.

Purpose: development of conceptual solutions for the use of geothermal coolant in the internal well heat exchanger of the injection well.

To achieve this goal, the research objectives are formulated:

- development of the basic scheme of the internal well heat exchanger with the geothermal heat carrier;

- modeling of the heat exchange process and calculation of the regime parameters of the implementation of a downhole heat exchanger with a geothermal heat carrier. 


\section{Research results and discussion}

Fig. 3 shows the proposed scheme of the combined injection well with an internal geothermal heat exchanger. The geothermal coolant is taken from a separate geothermal tank, which can be ground or formation water with high temperature. For the conditions of the Dnipro-Donetsk basin, the temperatures of formation waters at depths of about $2500-3000 \mathrm{~m}$ reach $80-110^{\circ} \mathrm{C}$. The coolant is pumped through the injection gas well in a parallel discharge pipe (column). Pipes can be arranged coaxially (heat exchanger "pipe in a pipe"), in parallel or mixed (coaxially-parallel) [25]. The Fig. 3 shows the heat transfer zone formed by the pipes of the internal heat exchanger of the well. These pipes cross the layers of rock from the surface to the water mirror of the sole of the oil-saturated formation. Heating the gas with a heat exchanger changes the PTC and the probability of hydration in the main endangered areas - the bottom of the injection gas column, the filtration zone of the face and bottomhole zone (shown in Figs. 2 and 3 with numbers 1-3). If it is necessary to use an injection well (Fig. 3) to raise the geothermal coolant to the surface (where a pump or hydraulic turbine is installed for its subsequent injection into the groundwater area), the geothermal coolant is fed through another inner column of the well. The submersible and / or surface pump (hydraulic turbine) in such a circuit solution is selected at the design stage. In the case of localization of the geothermal reservoir in the zone of high pressure and temperature of the side rocks, in the proposed scheme, the pump for water injection may be unnecessary due to a sufficient difference in formation pressure. Therefore, in the diagram of Fig. 3, pump and turbine at the top are not shown.

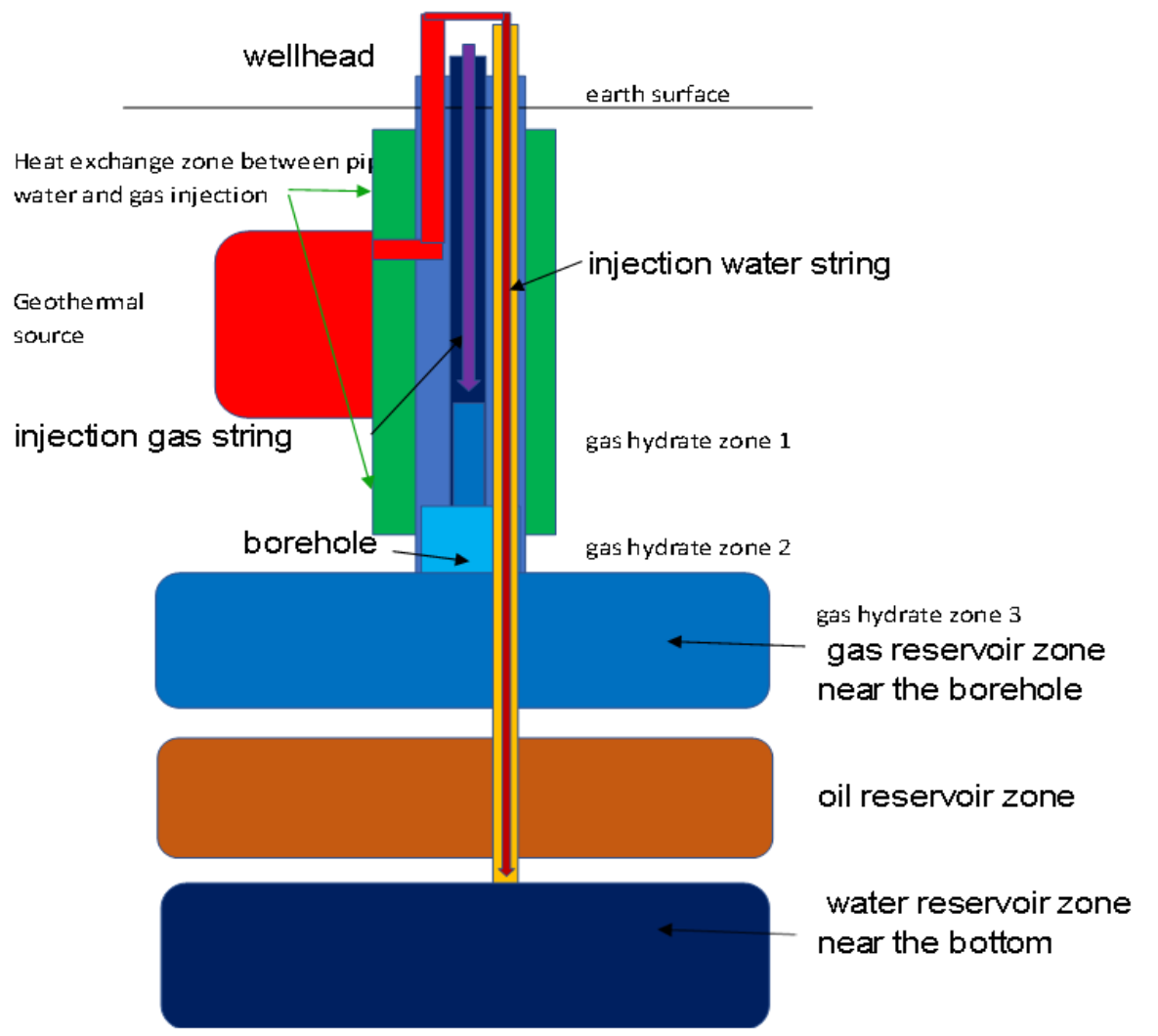

Fig. 3. Scheme of combined (for geothermal carrier and gas) injection well with internal geothermal heat exchanger. 
Thus, from the point of view of engineering reconstruction at transition from a typical flooding of oil deposit (Fig. 1) to the offered scheme of a well (Fig. 3), the following technological operations become necessary:

- intake of geothermal water from an appropriate source;

- supply of geothermal hot water with thermal insulation of individual parts of the well;

- injection of coolant into the well with a heat exchanger on a two-row or multi-row injection column.

At the same time there is an increase in the speed and turbulence of gas flows in the areas threatened by hydration.

To increase the selection of geothermal heat to the column with water and gas in the well can also be installed additional side trunks with heat pipes [26, 27].

The calculation of the proposed injection well involves three main stages that allow us to estimate the amount of geothermal water and energy in a particular parametric field based on the practice of operation of oil fields:

- determination of geothermal power required for sufficient heating of the gas in the injection gas column of the downhole heat exchanger in order to avoid hydration;

- determination of geothermal capacity required for pumping hot water into the oil field development object with a known reservoir pressure difference between the geothermal reservoir and the solenoid mirror of the oil-saturated formation (calculated with no pump);

- determination of the total geothermal energy for the implementation of no hydrate operation of the well according to the proposed scheme.

The change principle of PTC in the zones of injection well threatened by hydration formation - transition from critical to safe with a distance margin is shown in Fig. 4.

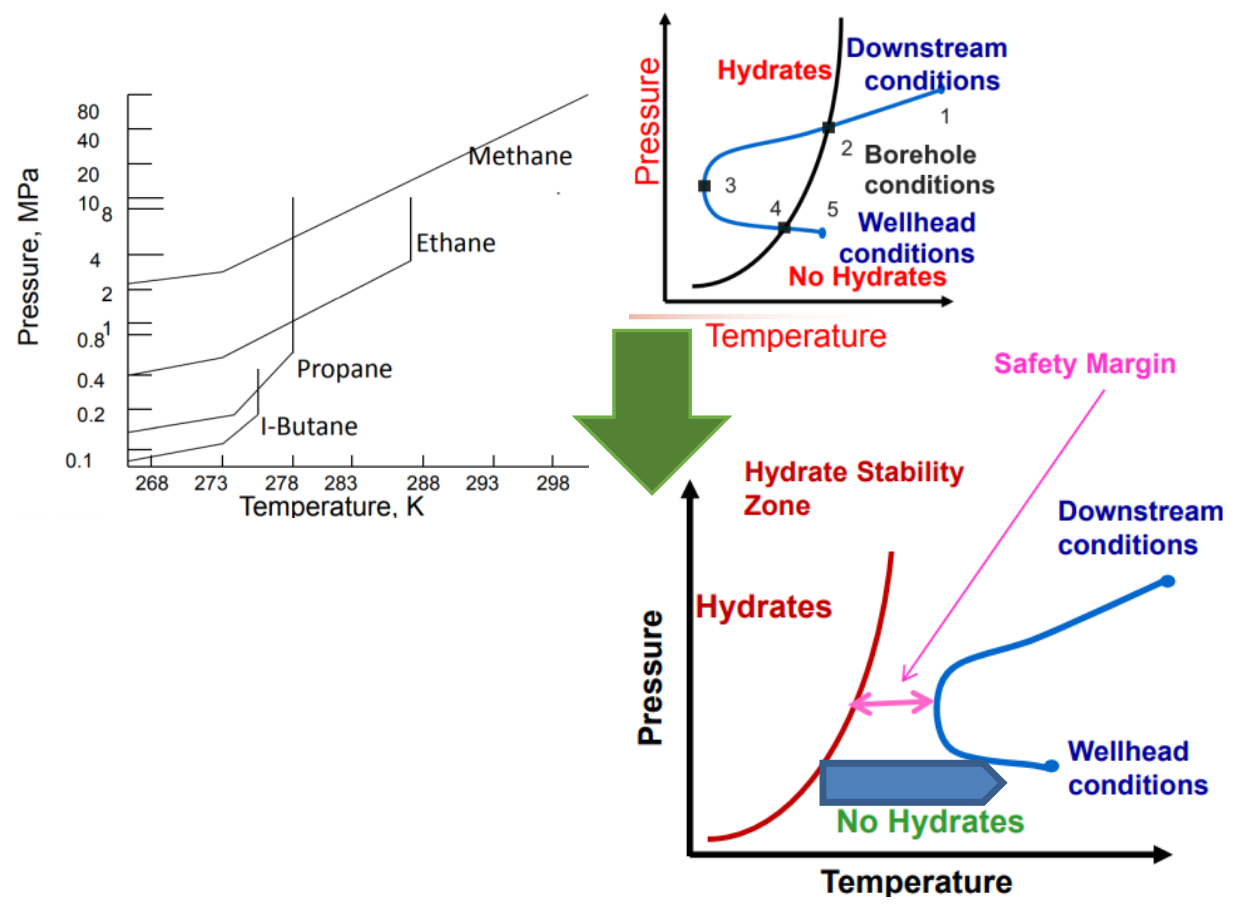

Fig. 4. PTC in the injection well from the boundary of the drainage zone to the wellhead: (a) option without the supply of geothermal coolant; (b) option with the supply of geothermal coolant; (c) hydrate formation zones for individual hydrocarbons. 
Let's analyze changes in pressure and temperature conditions in the zones of injection well threatened by hydration formation (Fig. 4). Curve $A$ reflects the pressure and temperature conditions in the gas flow of the injection well and the drainage zone of the oil reservoir. Curve $B$ is the curve of the limiting PTC of hydrate formation.

Point 1 on curve $A$ (Fig. 4a), corresponds to the boundary of the drainage zone of the oil reservoir, in which the temperature and pressure are maximum. Section 1-2 corresponds to the approach from the boundary of the drainage zone of the oil reservoir to the face; Point 2 is localized in the bottomhole zone. Section 2-3 corresponds to the bottomhole zone (bottomhole filtration zone); Point 3 is at the very bottom of the well. Section 3-4 corresponds to the bottom area of the injection gas column. Point 4 - the top of this endangered area of hydration.

When feeding a geothermal carrier, curve $\mathrm{A}$ is shifted to the right without intersecting with curve B of the boundary PTC of hydrate formation. Thus, the hydration zone between points 2-3-4 disappears, hydrates are not formed.

Fig. 4 shows that according to the composition of the injected natural gas, the temperature dependence of the pressure limit curve "hydrate - no hydrate" regime can be extrapolated by a quadratic equation and most of the endangered area will be near the face.

With the gas mass flow and water $Q_{m}$ gas in $Q_{m}$ water injection columns and heat exchanger with temperatures at the top and bottom $T_{\text {water borehole, }}, T_{\text {water wellhead }}, T_{\text {gas borehole }}$, $T_{\text {gas wellhead }}$ heat supply to the gas from the water will be determined by the equation:

$$
\begin{aligned}
W_{\text {heat exch }} & =Q_{\text {mwater }} \cdot C_{\text {pwater }} \cdot\left(T_{\text {water borehole }}-T_{\text {water wellhead }}\right)= \\
& =Q_{\text {mgas }} \cdot C_{p \text { gas }} \cdot\left(T_{\text {gas borehole }}-T_{\text {gas wellhead }}\right),
\end{aligned}
$$

where: $C_{p \text { gas }}$ and $C_{p \text { water }}$ are isobaric heat capacities of gas and water, respectively.

To heat the gas to the temperature $d T_{\text {gas }}=T_{\text {gas borehole }}-T_{\text {gas wellhead }}$ (Fig. 4), the first approximation can be considered $C_{p \text { gas }}$ - const and written according to (3):

$$
Q_{m \text { water }}=\frac{Q_{\text {mgas }} \cdot C_{\text {pgas }} \cdot d T}{Q_{p \text { water }} \cdot\left(T_{\text {water borehole }}-T_{\text {water wellhead }}\right)} .
$$

Equation (4) shows that depending on the mass flow rate of the gas and its properties, different amounts of geothermal energy (and, accordingly, the consumption of heated water) are required to avoid hydration. To estimate, take a practical example with gas flow reduced to standard conditions $Q_{q \text { gas norm }}=200$ thousand $\mathrm{m}^{3} / \mathrm{day}, C_{p}$ gas $=2400 \mathrm{~J} / \mathrm{kg} \cdot \mathrm{K}$ with a gradient of geothermal water $d T_{\text {water }}=60 \mathrm{~K}$. Heat capacity of water $C_{p \text { water }}=4200 \mathrm{~J} / \mathrm{kg} \cdot \mathrm{K}$. To be able to use formula (4), we need to convert the volume flow $Q_{q \text { gas }}$ into mass $Q_{m \text { gas }}$ for averaged PTC $P_{\text {gas av }}=15 \mathrm{MPa} ; T_{\text {gas } a v}=330 \mathrm{~K}$ according to the following equation:

$$
Q_{m \text { gas }}=Q_{q \text { gas }} \cdot \rho=S \cdot V \cdot \frac{\left(\rho_{\text {norm }} \cdot T_{\text {norm }} \cdot P_{\text {gas av }}\right)}{\left(T_{\text {gas av }} \cdot P_{\text {norm }} \cdot Z\right)}=\frac{\pi \cdot D^{2}}{4} \cdot 15 \cdot 100=4.34 \mathrm{~kg} / \mathrm{s},
$$

where: $\rho_{\text {norm }}$ - the density of the gas under standard conditions; $\rho$ - the density of the gas under operating conditions; $Z$ - the compressibility of the gas; $T_{n o r m}$ and $P_{n o r m}$ - respectively temperature and pressure under standard conditions, $S$ - cross-sectional area of the injection line; $V$ - the gas velocity. 
Substitute the obtained value of the mass flow rate $Q_{m}$ gas and the rest of the above numerical values in (4) and get $Q_{m}$ water $=0.41 \mathrm{~kg} / \mathrm{s}$. In terms of daily supply of coolant we get $35 \mathrm{t} /$ day. This value is included in the range of operating mode parameters of both injection and production wells [28].

Thermal geothermal power $E_{\text {water thermo }}$ is introduced taking into account the efficiency of the heat exchanger 0.3 :

$$
E_{\text {water thermo }}=Q_{m \text { water }} \cdot C_{p} \cdot d T_{\text {water }}=0.47 \cdot 4200 \cdot \frac{60}{0.30}=303 \mathrm{~kW} .
$$

Equation (4)-(6) is the first stage of calculations.

In the second stage, we find the geothermal capacity required to pump hot water in the oil field. For calculation we choose without pump option. We take the value of the pressure depression on the layer $d P=1 \mathrm{MPa}$ [29]. This pressure difference for different geological sections corresponds to the difference in geodetic heights between the geothermal reservoir and the object of development $1500-2500 \mathrm{~m}$, and the energy estimate of $E_{\text {water mech }}$ is:

$$
E_{\text {water mech }}=Q_{m \text { water }} \cdot \frac{d P}{\rho_{\text {water }}}=0.41 \cdot 1 \cdot \frac{10^{6}}{1}=410 \mathrm{~kW} \text {. }
$$

At the third stage of calculation of the injection well, we determine the total geothermal energy $E_{\text {summ }}$ for the implementation of no hydrate operation of the well according to the proposed scheme:

$$
E_{\text {summ }}=E_{\text {water thermo }}+E_{\text {water mech }}=303+410=713 \mathrm{~kW} .
$$

According to our calculations [30], the capacity of one geothermal well discovered at the oil depths of the Dnipro-Donetsk basin varies in the range of 1-3 MW. Thus, this is sufficient for the joint operation of geothermal and oil wells injection fund. In the critical zones of the injection well, the equilibrium temperature is maintained above the temperature of hydrate formation, the dependence on which, the pressure at different relative densities according to (1)-(5) is shown in Fig. 5.

Fig. 5 shows that when the relative density of gas in air from 0.5 to 0.75 and pressure from 7.5 to $15 \mathrm{MPa}$ (step - 2.5 MPa), the equilibrium temperature of hydrate formation in the gas well changes to $25 \mathrm{~K}$. Therefore, to regulate the equilibrium temperature of hydration to $25-30 \mathrm{~K}$, it's required a power according to (6)-(8) of 320-360 $\mathrm{kW}$.

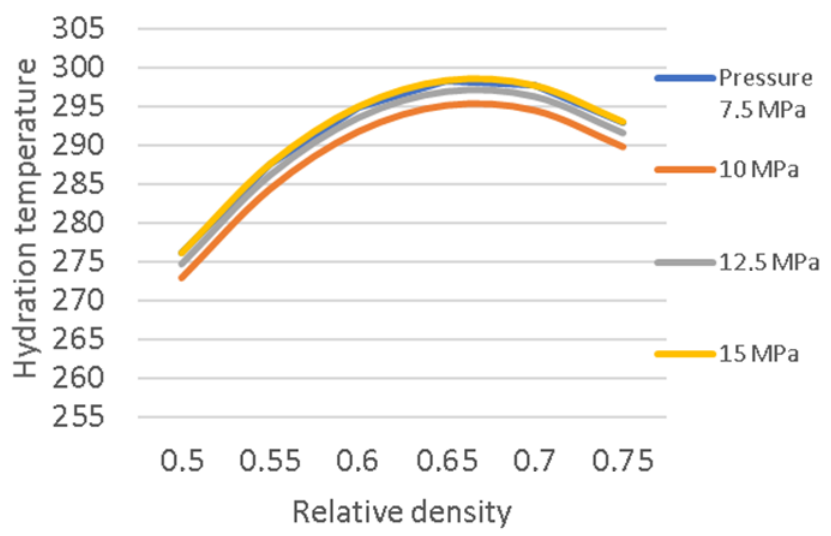

Fig. 5. Dependence of the equilibrium temperature of hydrate formations in natural gas on the relative density by air (specific gravity) at different operating pressures. 
In addition, the constant introduction of geothermal energy into the rock, which has a high heat capacity, gradually heats it $[31,32]$. This reduces the risk of hydration over time. Detailed consideration and analysis of this phenomenon is the subject of a separate study.

\section{Conclusions}

1. The scheme of the internal downhole heat exchanger with the geothermal heat carrier, which includes a supply line of the geothermal carrier through the heat exchange surface of the injection well into the productive reservoir of the oil field. The scheme provides targeted utilization of thermobaric energy of a geothermal source to eliminate hydration in the injection well.

2. A mathematical apparatus for describing the process of heat utilization and heat exchange in an injection well is proposed. On a specific example, and according to the proposed scheme, the calculation of the total geothermal energy is required for no hydrate implementation operation on the injection well of the oil field. It is established that the capacity of one geothermal well discovered at the oil depths of the Dnipro-Donetsk basin is sufficient to eliminate hydration in 1-3 injection wells, which determines the feasibility of their joint work.

The authors are thankful to the Ukrainian Research Institute of Natural Gas in Kharkiv for providing information on the oil and gas field in eastern Ukraine for use in preparation of the article.

\section{References}

1. Jianzhou Li, Lijun Guan, Yonghai Gao, \& Baojiang Sun. (2012). Prediction method of gas hydrates under condition of different productions in well testing of deep water gas well. Well Test, 21(2), 17-19. https://doi.org/10.1016/j.petlm.2016.06.004

2. Bondarenko, V., Kovalevs'ka, I., \& Ganushevych, K. (2014). Progressive technologies of coal, coalbed methane, and ores mining. London, United Kingdom: CRC Press, Taylor \& Francis Group. https://doi.org/10.1201/b17547

3. Pivnyak, G., Bondarenko, V., \& Kovalevska, I. (2015). New developments in mining engineering 2015. London, United Kingdom: CRC Press, Taylor \& Francis Group. https://doi.org/10.1201/b19901

4. Shukai Jin, Chong Zhang, Wenbo Meng, Yi Yu, Fabin Xu, \& Zhao Dong (2015). Gas hydrate risk and preventative measures for drilling and completion operations in LS 17-2 deep water gas field. China Offshore Oil Gas, 27(4), 93-101.

5. Kujawa, T., Nowak, W., \& Stachel, A.A. (2006). Utilization of existing deep geological wells for acquisitions of geothermal energy. Energy, 31(5), 650-664. https://doi.org/10.1016/j.energy.2005.05.002

6. Angrisani, G., Diglio, G., Sasso, M., Calise, F., \& Dentice d'Accadia, M. (2016). Design of a novel geothermal heating and cooling system. Energy Conversion and Management, (108), 144-159. https://doi.org/10.1016/j.enconman.2015.11.001

7. Alkhasov, A.B., \& Alkhasova, D.A. (2018). Heat exchangers for utilization of the heat of high-temperature geothermal brines. Thermal Engineering, 65(3), 155-159. https://doi.org/10.1134/S0040601518030035

8. Katipot Inkong, Hari Prakash Veluswamy, Pramoch Rangsunvigit, Santi Kulprathipanja, \& Praveen Lingand. (2019). Innovative approach to enhance the methane hydrate formation at near ambient temperature and moderate pressure for gas storage applications. Industrial \& Engineering Chemistry Research, Just Accepted Manuscript. https://doi.org/10.1021/acs.iecr.9b04498

9. Hao, Y., Li, X., Shuxia, Li, Lu, G., Liu, Y., \& Wei, X. (2018). Heat conduction and thermal convection on thermal front movement during natural gas hydrate thermal stimulation exploitation. IFP Energies Nouvelles, 73(40). https://doi.org/10.2516/ogst/2018046 
10. Ingrid Azevedode Oliveira, Iuri Soter Viana Segtovich, Amaro Gomes Barreto Jr., Frederico Wanderley Tavares. (2017). Accurate thermodynamic description of vapor-liquid and solid-liquid equilibria of THF, water and gas hydrates with a unique set of parameters. The Journal of Chemical Thermodynamics, (117), 60-67. https://doi.org/10.1016/j.jct.2017.08.003

11. Zhenhao, D., Ding, L., Yali, C., \& Rui, S. (2011). The influence of temperature, pressure, salinity and capillary force on the formation of methane hydrate. Geosciences Frontiers 2011, (2), 125-135. https://doi.org/10.1016/j.gsf.2011.03.009

12. Shagapov, V.S., Khasanov, M.K., \& Musakaev, N.G. (2008). Formation of a gas hydrates due to injection of a cold gas into a porous reservoir partly saturated by water. Journal of Applied Mechanics and Technical Physics, (49), 462-472. https://doi.org/10.1007/s10808-008-0062-y

13. Yanli Guo, Baojiang Sun, Keke Zhaob, \& Hongkun Zhang. (2016). A prediction method of natural gas hydrate formation in deepwater gas well and its application. Petroleum, 2(3), 296-300. https://doi.org/10.1016/j.petlm.2016.06.004

14. Zhi Zhong, Siyan Liu, Timothy R. Carrc, Ali Takbiri-Borujeni, Mohammad Kazemie, \& Qinwen Fub. (2019). Numerical simulation of water-alternating-gas process for optimizing EOR and carbon storage. Energy Procedia, (158), 6079-6086. https://doi.org/10.1016/j.egypro.2019.01.507

15. Bondarenko, V., Kovalevska, I., Astafiev, D., \& Malova, O. (2018). Examination of phase transition of mine methane to gas hydrates and their sudden failure - Percy Bridgman's effect. Solid State Phenomena, (277), 137-146. https://doi.org/10.4028/www.scientific.net/SSP.277.137

16. Bondarenko, V., Svietkina, O., \& Sai, K. (2018). Effect of mechanoactivated chemical additives on the process of gas hydrate formation. Eastern-European Journal of Enterprise Technologies, 1(6(91)), 17-26. https://doi.org/10.15587/1729-4061.2018.123885

17. Maksymova, E., Ovchynnikov, M., Lysenko, R., \& Kostrytska, S. (2018). Physical and chemical methods of methane utilization in Ukrainian coal mines. Solid State Phenomena, (277), 147-156. https://doi.org/10.4028/www.scientific.net/SSP.277.147

18. Dreus, A.Yu., Bondarenko, V.I., Biletskyi, V.S., \& Lysenko, R.S. (2020). Mathematical simulation of heat and mass exchange processes during dissociation of gas hydrates in a porous medium. Naukovyi Visnyk Natsionalnoho Hirnychoho Universytetu, 5(179). https://doi.org/10.33271/nvngu/2020-5/033

19. Bondarenko, V., Svietkina, O., Lysenko, R., \& Liu, B. (2020). Methane gas hydrates influence on sudden coal and gas outbursts during underground mining of coal deposits. E3S Web of Conferences, (201), 01002. https://doi.org/10.1051/e3sconf/202020101002

20. Bondarenko, V., \& Sai, K. (2018). Process pattern of heterogeneous gas hydrate deposits dissociation. Naukovyi Visnyk Natsionalnoho Hirnychoho Universytetu, (2), 21-28. https://doi.org/10.29202/nvngu/2018-2/4

21. Kelland, M.A., Svartaas, T.M., \& Dybvik, L. (1995). A new generation of gas hydrate inhibitors. Society of Petroleum Engineers, 529. https://doi.org/10.2118/30695-MS

22. Gallagher, K.S., Grübler, A., Kuhl, L., Nemet, G., \& Wilson, C. (2012). The energy technology innovation system. Annual Review of Environment and Resources, (37), 137-162.

23. Alimonti, C., \& Soldo, E. (2016). Study of geothermal power generation from a very deep oil well with a wellbore heat exchanger. Renewable Energy, (86), 292-301. https://doi.org/10.1016/j.renene.2015.08.031

24. Alimonti, C., Soldo, E., Bocchetti, D., \& Berardi, D. (2018). The wellbore heat exchangers: A technical review. Renewable Energy, (123), 353-381. https://doi.org/10.1016/j.renene.2018.02.055

25. Asif, M., Yao, J., Fan D., Bongole, K., Liu J., \& Zhang, X. (2019). Potential for heat production by retrofitting abandoned gas wells into geothermal wells. PLOS ONE, 14(8), e0220128. https://doi.org/10.1371/journal.pone.0220128

26. Chen, C., Shao, H., Naumov, D., Kong, Y., Tu, K., \& Kolditz, O. (2019). Numerical investigation on the performance, sustainability, and efficiency of the deep borehole heat exchanger system for building heating. Chen et al. Geotherm Energy, (7). https://doi.org/10.1186/s40517-019-0133-8 
27. Fyk, M., Biletskyi, V., Ryshchenko, I., \& Abbood, M. (2019). Improving the geometric topology of geothermal heat exchangers in oil bore-holes. E3S Web of Conferences, (123), 01023. https://doi.org/10.1051/e3sconf/201912301023

28. Fyk, M., Fyk, I., Biletsky, V., Oliynyk, M., Kovalchuk, Yu., Hnieushev, V., \& Shapchenko, Yu. (2018). Theoretical and applied aspects of using a thermal pump effect in gas pipeline systems. Eastern-European Journal of Enterprise Technologies, 1(8(91)), 39-48. https:/doi.org/10.15587/1729-4061.2018.121667

29. Azin, R., Sedaghati, H., Fatehi, R., Osfouri, S., \& Sakhaei, Z. (2019). Production assessment of low production rate of well in a supergiant gas condensate reservoir: application of an integrated strategy. Journal of Petroleum Exploration and Production Technology, (9), 543-560. https://doi.org/10.1007/s13202-018-0491-y

30. Fyk, M., Biletskyi, V., \& Abbud, M. (2018). Resource evaluation of geothermal power plant under the conditions of carboniferous deposits usage in the Dnipro-Donetsk depression. E3S Web of Conferences, (60), 00006. https://doi.org/10.1051/e3sconf/20186000006

31. Fyk, M., Biletskyi, V., Fyk, I., Bondarenko, V., \& Al-Sultan, M. (2019). Improvement of an engineering procedure for calculating the non-isothermal transportation of a gas-liquid mixture. Eastern-European Journal of Enterprise Technologies, 3(5(99)), 51-60. https://doi.org/10.15587/1729-4061.2019.167198

32. Ganguly, S. (2018). Exact solution of heat transport equation for a heterogeneous geothermal reservoir. Energies, 11(11), 2935. https://doi.org/10.3390/en11112935 